\title{
A Rare Case of Secundum Atrial Septal Defect with Intractable Heart Failure after Coarctectomy by an Infant
}

\author{
Zornitsa Vassileva*, Anna Kaneva-Nencheva, Georgi Konstantinov, Kiparisiya Nenova and Dimiter Pechilkov \\ Department of Pediatric Cardiology, National Heart Hospital - Sofia, Bulgaria
}

Submission: June 28, 2019; Published: July 10, 2019

*Corresponding author: Zornitsa Vassileva, Department of Pediatric Cardiology, National Heart Hospital Konjovitsa 65 Str, Sofia 1309 , Bulgaria

\begin{abstract}
We present a case of resistant to medical treatment heart failure due to significant shunting through a secundum atrial septal defect by a 3-month old infant who underwent coarctectomy due to critical coarctation of the aorta at the age of 15 days. The tachydyspnea and failure to thrive persisted despite the successful resection of the coarctation and resolved very rapidly after subsequent operative closure of the atrial septal defect.
\end{abstract}

Keywords: Secundum atrial septal defect; Heart failure; Infant; Coarctation of the aorta; Coarctectomy

Abbreviations: ASD II: Secundum Atrial Septal Defect; PVR: Pulmonary Vascular Resistance; CHF: Congestive Heart Failure

\section{Introduction}

ASD II is a common congenital heart disease which is typically asymptomatic in infancy and childhood. Hemodynamically significant shunting through the defect with pulmonary over circulation and heart failure symptoms is very rare by infants. If the ASD II is left untreated, approximately one third of the patients suffer from pulmonary hypertension in the third or fourth decade of life.

\section{Case Presentation}

The patient was first seen at our clinic at the age of 13 days. He was born from a normal pregnancy and delivery through Cesarean section because of maternal indications. The early neonatal period was uneventful, the baby was considered healthy and was dismissed home at the age of 5 days. At the age of 12 days his condition suddenly deteriorated, and he was brought to the pediatrician where he presented in cardiogenic shock and was immediately referred to the emergency.

The baby was admitted at our clinic in very poor clinical condition, with diminished peripheral pulses, hepatomegaly, anuria. The blood gas analysis showed severe lactate acidosis. The echocardiography revealed a critical coarctation of the aorta with ductal-dependent systemic circulation, impaired right and left ventricular function and an atrial septal defect. He was treated with prostaglandins and catecholamine infusion.
Two days later, after stabilization of the clinical condition, the patient was operated - resection of the coarctation and endto-end anastomosis was performed through left thoracotomy. The operation was considered successful as the coarctation was resolved, with restoration of normal blood flow through the aortic isthmus.

What was noticed on the postoperative echo was that the atrial septal defect type ostium secundum was quite large (Figure 1), with significant left-to right shunting and with marked right ventricular dilation (Figure 2). The left ventricle was hypertrophic, with reversed E/A ratio of the flow through the mitral valve. The left ventricle appeared small in relation to the markedly dilated right ventricle, but the left ventricular size was normal for the weight and the height of the patient.

Despite the successful operation, the lack of infection or any other problem the symptoms of CHF by the baby persisted. He had feeding difficulties, failure to thrive, tachypnea and dyspnea, persistent hepatomegaly which did not improve significantly during treatment with diuretics and vasodilators. The X-ray showed moderate cardiomegaly and pulmonary over circulation.

Every attempt to switch form intravenous to oral diuretic therapy was associated with deterioration of the clinical condition of the baby, with an increase of the tachypnea and dyspnea and 


\section{Journal of Cardiology \& Cardiovascular Therapy}

with reduction of the oral intake because of fatigue and exhaustion. His height and weight remained below the 3rd percentile for age.

Since we could not achieve any improvement with conservative measures and because of the apparently significant left-to-right shunting through the atrial septal defect with right ventricle/ left ventricle index $>1$, we decided that we needed to estimate objectively the significance of the shunting at atrial level. Three months after the operation a diagnostic cardiac catheterization was performed. It showed a large left-to-right shunting at atrial level with ratio between the pulmonary $(\mathrm{Qp})$ and systemic blood flow (Qs) of 4/1, with elevated pulmonary artery pressure (40 mmHg peak systolic pressure) and normal PVR. There was no rest gradient at the level of the coarctation repair.

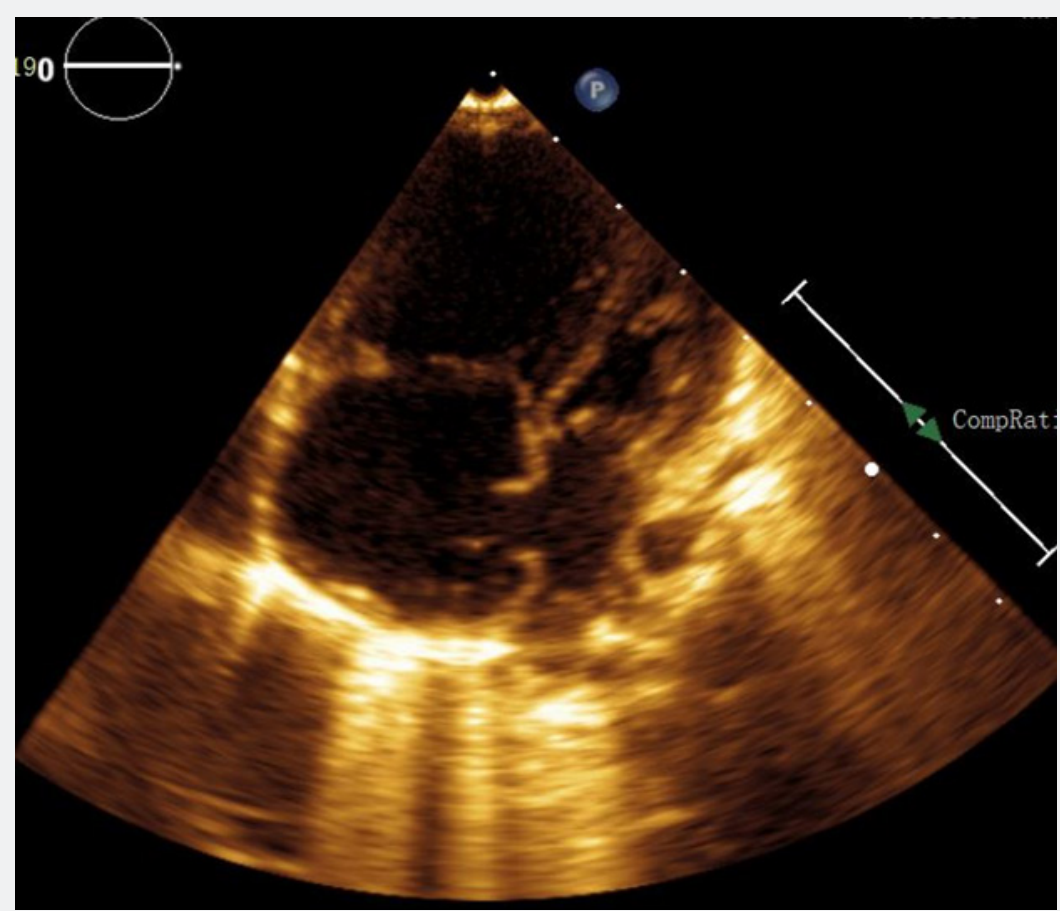

Figure 1: Four chamber view 2 months after coarctectomy showing a large ASD II and right ventricular dilation.

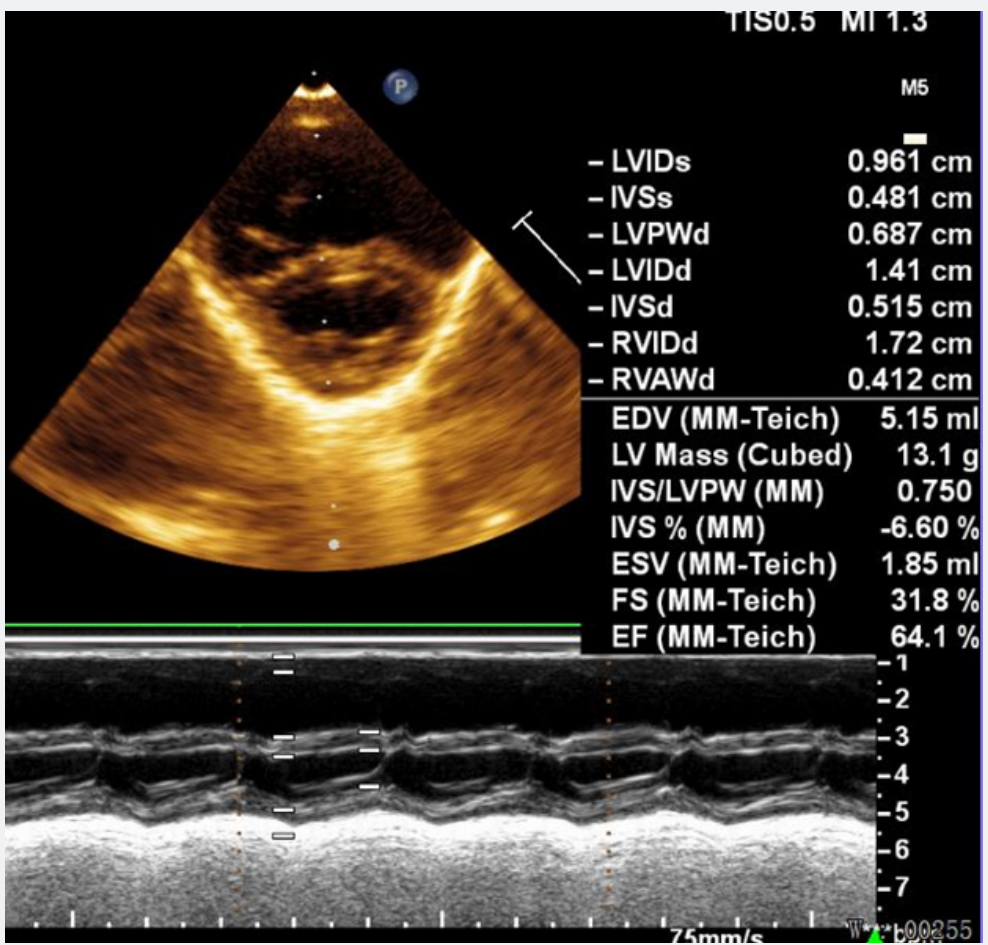

Figure 2: Short axis view demonstrating marked dilation of the right ventricle giving an impression for small size of the left ventricle. 
The baby was re-operated 2 days after the cardiac catheterisation (at the age of 3.5 months) and the atrial septal defect was closed with a $3 \mathrm{~mm}$ fenestrated pericardial patch. The early postoperative period was uneventful, the clinical condition of the child improved every other day, with marked reduction of the heart failure symptoms. The postoperative echo showed regression of the right ventricular dilation and of the left ventricular hypertrophy and normalization of the left ventricular diastolic function (Figure 3).

The baby could overcome all feeding difficulties, began to gain weight and was dismissed home 18 days after the operation with low dose oral diuretic and vasodilator.

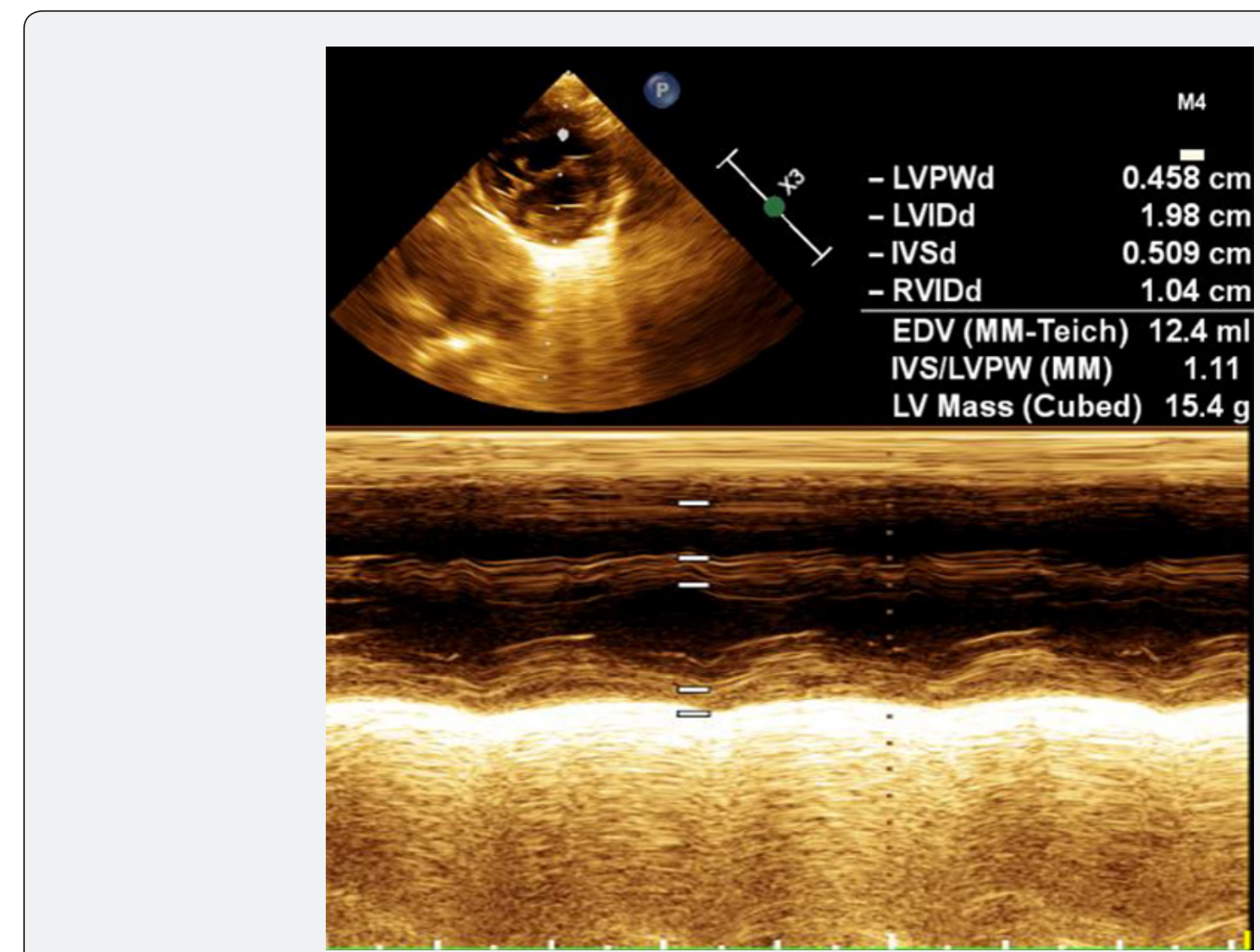

Figure 3: Postoperative echo 1 week after closure of the ASD II showing regression of the right ventricular dilation.

\section{Discussion}

This patient represents a rare case of hemodynamically significant atrial septal defect with CHF symptoms in infancy. Probably the left ventricular hypertrophy as a result of the coarctation lead to restriction of the diastolic filling of the left ventricle and consequent increase of the left-to right shunting through the large atrial septal defect which reached significant levels.

Our initial idea was that with time the hypertrophy of the left ventricle would decrease, its distensibility would improve and the left-to-right shunting at atrial level would diminish. However, the baby could not tolerate the significant shunting and his clinical condition did not let us wait any longer. After closure of the atrial septal defect we observed spectacular improvement of the heart failure symptoms.

It is possible that the physiological fall of PVR during the first weeks of life also contributed to the increase of the shunting at atrial level. The combination of restrictive filling pattern of the left ventricle and the unusually rapid rise in the compliance of the right ventricle in the context of lowering PVR lead to a pronounced increase in the left-to-right shunting through the ASD II.

After search of the scientific literature we found few case reports and case series of symptomatic infants with atrial septal defects which required early closure.

Lammers A et al. [1] from Germany report 24 infants over the course of 12 years (January 1990-August 2002) with isolated ASD II who needed surgical closure of the defect within the first year of life because of persistent symptoms - tachydyspnea, failure to thrive, recurrent respiratory infections. Four babies needed artificial ventilation preoperatively.

The children were followed for a mean period of $46+/-3$ months (range, 4-125 months) and the pulmonary artery pressure had normalized in 11 of the 13 children who had preoperative pulmonary hypertension. One baby died of persistent pulmonary hypertension. In nearly all patient's improvement of the clinical symptoms, growth, and development was observed. All ventilatordependent children could be weaned shortly after atrial septal defect closure. 
Ten patients in this series had additional problems prematurity with chronic lung disease, hepato-omphalocele and congenital diaphragmatic hernia but none of them had congenital heart disease as our patient.

Bull C et al. [2] have published a case series of six infants with isolated atrial septal defect which was symptomatic and required surgical closure [2]. When they were first seen the age of the patients ranged from 6 days to 6 months; three of them had severe congestive failure, four had failure to thrive, and one had a respiratory tract infection.

All six children were operated because it was impossible to control the heart failure medically and all were below the 3rd centile for height and weight. Their age at the time of the operation was between three and nine months.

Andrews R [3] report 6 patients with symptomatic ASD which required surgical closure in infancy. According to the authors it is very important to exclude other cardiac or pulmonary abnormalities in these cases. It is possible that not only the ASD itself, but the additional presence of left-sided obstructive lesions or other shunts lead to pronounced pulmonary hypertension. If such aggravating factros are present closure of the ASD will not suffice to eliminate the symptoms.

By our patient the symptoms persisted despite the successful operation of the coarctation but resolved very rapidly after closure of the ASD II which shows that the shunting at atrial level was the leading problem.

\section{Conclusion}

The presented case shows that even though symptomatic ASD II in infancy is not common, it can cause refractory to medical treatment $\mathrm{CHF}$ and may require prompt surgical treatment.

\section{References}

1. Lammers A, Hager A, Eicken A, Lange R, Hauser M, Hess J (2005) Need for closure of secundum atrial septal defect in infancy. J Thorac Cardiovasc Surg 129(6): 1353-1357.

2. Bull C, Deanfield J, de Leval M, Stark J, Taylor JFN, et al. (1981) Correction of isolated secundum atrial septal defect in infancy. Arch Dis Child 56: 784-786.

3. Andrews R, Tulloh R, Magee A, Anderson D (2002) Atrial septal defect with failure to thrive in infancy: hidden pulmonary vascular disease? Pediatr Cardiol 23(5): 528-530.

Your next submission with Juniper Publishers
will reach you the below assets
- Quality Editorial service
- Swift Peer Review
- Reprints availability
- E-prints Service
- Manuscript Podcast for convenient understanding
- Global attainment for your research
- Manuscript accessibility in different formats
( Pdf, E-pub, Full Text, Audio)
- Unceasing customer service
Track the below URL for one-step submission
https://juniperpublishers.com/online-submission.php

